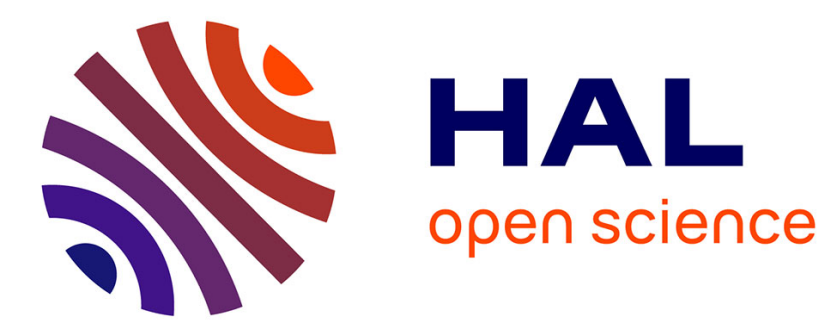

\title{
Comment on "Gravity fall of light: An outline of a general relativity test"
}

Bernard Linet

\section{To cite this version:}

Bernard Linet. Comment on "Gravity fall of light: An outline of a general relativity test". Physical Review D, 2004, 70, pp.048101. 10.1103/PhysRevD.70.048101 . hal-00015331

\section{HAL Id: hal-00015331 \\ https://hal.science/hal-00015331}

Submitted on 6 Dec 2005

HAL is a multi-disciplinary open access archive for the deposit and dissemination of scientific research documents, whether they are published or not. The documents may come from teaching and research institutions in France or abroad, or from public or private research centers.
L'archive ouverte pluridisciplinaire HAL, est destinée au dépôt et à la diffusion de documents scientifiques de niveau recherche, publiés ou non, émanant des établissements d'enseignement et de recherche français ou étrangers, des laboratoires publics ou privés. 


\title{
Comment on "Gravity fall of light: An outline of a general relativity test"
}

\author{
Bernard Linet \\ Laboratoire de Mathématiques et Physique Théorique, \\ CNRS/UMR 6083, Université François Rabelais, F-37200 Tours, France
}

(Dated: December 6, 2005)

\begin{abstract}
In the paper of Díaz-Miguel [Phys. Rev. D 69, 027101 (2004)], it is argued that the vertical deflection of a photon in the vicinity of the Earth surface is different from the one in a uniform gravitational field. We show by a detailed analysis that this result is obtained in coordinates which are different from those that should normally be used.
\end{abstract}

In a recent paper [1], Díaz-Miguel determined the vertical deflection of a photon during a short flight in the vicinity of the Earth surface. Using the standard coordinates to express the Schwarschild metric describing the Earth gravitational field, he derived a result which is different from the vertical deflection calculated in the uniform gravitational field. We point out in this comment that his result is misleading because it is necessary to pay attention to the fact that the coordinates have no physical meaning in general relativity.

We start from the Schwarschild metric written in the standard coordinates $(t, r, \theta, \varphi)$

$$
d s^{2}=\left(1-\frac{2 m}{r}\right) d t^{2}-\left(1-\frac{2 m}{r}\right)^{-1} d r^{2}-r^{2} d \theta^{2}-r^{2} \sin ^{2} \theta d \varphi^{2} .
$$

We consider a world line $\mathcal{C}$ located at $r=R, \theta=\pi / 2$ and $\varphi=0$ with $R>2 m$. We do not take $\theta=0$ to avoid a coordinate singularity of metric (11). In a previous work [2], we have explicitly written the coordinates $\left(y^{0}, y^{i}\right)$ which ensure, in a small neighborhood of the world line $\mathcal{C}$ defined by $y^{i}=0$, that metric (1) takes the form

$$
\begin{gathered}
d s^{2}=\left(1+2 g y^{1}\right)\left(d y^{0}\right)^{2}-\left(d y^{1}\right)^{2}-\left(d y^{2}\right)^{2}-\left(d y^{3}\right)^{2} \\
\text { with } g=\frac{m}{R^{2} \triangle} \quad \text { where } \triangle=\left(1-\frac{2 m}{R}\right)^{1 / 2},
\end{gathered}
$$

up to the second-order corrections in $y^{i}$. They are related to $(t, r, \theta, \varphi)$ by the transformation

$$
\begin{aligned}
t & =\frac{1}{\triangle} y^{0}, \\
r & =R+\triangle y^{1}+\frac{m}{2 R^{2}}\left(y^{1}\right)^{2}+\frac{\triangle^{2}}{2 R}\left[\left(y^{2}\right)^{2}+\left(y^{3}\right)^{2}\right], \\
\theta & =\frac{\pi}{2}+\frac{1}{R} y^{2}-\frac{\triangle}{R^{2}} y^{1} y^{2}, \\
\varphi & =\frac{1}{R^{3}} y^{3}-\frac{\triangle}{R^{2}} y^{1} y^{3}
\end{aligned}
$$

up to the third-order corrections in $y^{i}$.

So, the Schwarzschild metric coincides in a small neighborhood of the world line $\mathcal{C}$ with the uniform gravitational field $g^{i}=-g \delta_{1}^{i}$. The coordinates $\left(y^{0}, y^{i}\right)$ are the Fermi coordinates associated with the accelerated observer having the world line $\mathcal{C}$ [3]. At the Earth surface, the acceleration due to the Earth gravity is $g$ and it can be approximated by $m / R^{2}$. Within the interpretation of general relativity, the coordinates $\left(y^{i}\right)$ are measured by rules in a small neighborhood of the world line $\mathcal{C}$.

The propagation of light in metric (2) is well known. We can easily determine the vertical deflection for a photon which is horizontally emitted at $y^{1}=0$ and $y^{2}=0$ in the plane $y^{3}=0$. After the flight of the photon, we have

$$
y^{1}=-\frac{1}{2} g(\delta l)^{2}, \quad y^{2}=\delta l .
$$

*Electronic address: linet@phys.univ-tours.fr 
We apply formulas (3) with $y^{i}$ given by (4) but we keep only the terms linear in $m$ in accordance with the approximation of Díaz-Miguel. For a photon emitted horizontally at $r=R$ and $\theta=\pi / 2$ in the plane $\varphi=0$, we find after the flight of the photon

$$
r=R-\frac{1}{2} g(\delta l)^{2}+\frac{1}{2 R}(\delta l)^{2}-g(\delta l)^{2}, \quad \theta=\frac{\pi}{2}+\frac{1}{R} \delta l .
$$

In order to compare with the result of Díaz-Miguel, we express (5) in the coordinates $(x, y)$ related in our case to $(r, \theta)$ by

$$
x=-r \cos \theta, \quad y=r \sin \theta
$$

We are now in a position to calculate from (4) the vertical deflection in these coordinates. After the flight of the photon, we find

$$
x=\delta l, \quad y=R-\frac{3}{2} g(\delta l)^{2}
$$

which is the result of Díaz-Miguel.

However, our comment shows that formula (7) is coordinate dependent In a terrestrial laboratory, we must take metric (2) to describe the gravitational field. The coordinates $\left(y^{i}\right)$ are assimilated to the Galilean coordinates of the terrestrial laboratory in which there exists a uniform gravitational field. The measurement of the vertical deflection in the laboratory is given by the value of the coordinate $y^{1}$ by formula (幽, i.e. $-g(\delta l)^{2} / 2$.

[1] E. Díaz-Miguel, Phys. Rev. D 69, 027101 (2004).

[2] B. Léauté, and B. Linet, Int. J. Theor. Phys. 22, 67 (1983).

[3] C.W. Misner, K.S. Thorne, and J.A. Wheeler, Gravitation (W.H. Freeman and Company, San Francisco, 1973). 